\title{
Somatic mutations in adrenocortical carcinoma with primary aldosteronism or hyperreninemic hyperaldosteronism
}

\author{
Isobel C Mouat ${ }^{1}$, Kei Omata1,2, Andrew S McDaniel1,2, Namita G Hattangady³, Debnita Talapatra3 , Andi K Cani1,2, \\ Daniel H Hovelson 2,4, Scott A Tomlins ${ }^{1,2,5,6}$, William E Rainey7, Gary D Hammer ${ }^{3,7}$, Thomas J Giordano 1,3,5 and \\ Tobias Else ${ }^{3,5}$ \\ 'Department of Pathology, University of Michigan Medical School, Ann Arbor, Michigan, USA \\ 2Michigan Center for Translational Pathology, Department of Pathology, University of Michigan Medical School, Ann Arbor, Michigan, USA \\ 3Division of Metabolism, Endocrinology \& Diabetes, Department of Internal Medicine, University of Michigan Medical School, Ann Arbor, Michigan, USA \\ ${ }^{4}$ Department of Computational Medicine and Bioinformatics, University of Michigan Medical School, Ann Arbor, Michigan, USA \\ ${ }^{5}$ Comprehensive Cancer Center, University of Michigan Medical School, Ann Arbor, Michigan, USA \\ ${ }^{6}$ Department of Urology, University of Michigan Medical School, Ann Arbor, Michigan, USA \\ ${ }^{7}$ Department of Molecular and Integrative Physiology, University of Michigan Medical School, Ann Arbor, Michigan, USA
}

Correspondence should be addressed to T Else: telse@umich.edu

\begin{abstract}
Several somatic mutations specific to aldosterone-producing adenomas (APAs) have been described. A small proportion of adrenocortical carcinomas (ACCS) are associated with hyperaldosteronism, either primary aldosteronism or hyperreninemic hyperaldosteronism. However, it is unknown whether they harbor mutations of the same spectrum as APAs. The objective of this study is to describe the clinical phenotype and molecular genotype of ACCs with hyperaldosteronism, particularly the analysis for common APA-associated genetic changes. Patients were identified by retrospective chart review at a specialized referral center and by positive staining for CYP11B2 of tissue microarrays. Twenty-five patients with ACC and hyperaldosteronism were initially identified by retrospective chart review, and tissue for further analysis was available on 13 tumors. Seven patients were identified by positive staining for CYP11B2 in a tissue microarray, of which two were already identified in the initial chart review. Therefore, a total number of 18 patients with a diagnosis of ACC and features of either primary aldosteronism or hyperreninemic hyperaldosteronism were therefore included in the final study. Mutational status for a select list of oncogenes, tumor suppressor genes and genes known to carry mutations in APAs were analyzed by next-generation sequencing. Review of clinical data suggested autonomous aldosterone production in the majority of cases, while for some cases, hyperreninemic hyperaldosteronism was the more likely mechanism. The mutational landscape of ACCs associated with hyperaldosteronism was not different from ACCs with a different hormonal phenotype. None of the ACCs harbored mutations of known APA-associated genes, suggesting an alternative mechanism conferring aldosterone production.
\end{abstract}

\author{
Key Words \\ - primary aldosteronism \\ - adrenocortical carcinoma \\ - next-generation sequencing \\ - hyperreninemic \\ hyperaldosteronism
}

https://erc.bioscientifica.com https://doi.org/10.1530/ERC-18-0385
(C) 2019 Society for Endocrinology Published by Bioscientifica Ltd. Printed in Great Britain
Endocrine-Related Cancer (2019) 26, 217-225 


\section{Introduction}

Primary aldosteronism (PA) is the most common identifiable endocrine cause for hypertension and increased aldosterone levels are thought to pose health risk due to direct effects on the vasculature, heart and kidney. Most patients with PA have a benign adrenal adenoma or bilateral hyperplasia. Adrenocortical carcinoma (ACC), however, is a very rare cause of increased aldosterone levels, and a recent literature review identified only 58 reported patients (Seccia et al. 2005). ACC is a malignant tumor with an often unfavorable prognosis (Else et al. 2014a). Roughly $50-60 \%$ of ACCs produce active steroid hormones, most often glucocorticoids and/or adrenal androgens leading to Cushing syndrome and/or virilization and hirsutism. Only $3-5 \%$ of all ACC patients are reported to have suspected high aldosterone levels (Seccia et al. 2005, Else et al. 2014a,b). Currently it is unknown whether there are any genetic differences between aldosterone-producing and non-aldosterone-producing ACC with regards to their mutational landscape.

Most benign aldosterone-producing adenomas have mutations in ion channels affecting membrane conductance and polarization and subsequently intracellular calcium levels (Monticone et al. 2015). In particular, somatic mutations in KCNJ5, ATP1A1, ATP2B3 and CACNA1D and a germline mutation in CACNA1H have been described (Choi et al. 2011, Beuschlein et al. 2013, Scholl et al. 2013, 2015).

Recently, the somatic mutational landscape of ACC has been described in three large studies (Assie et al. 2014, Juhlin et al. 2015, Zheng et al. 2016). The most common alterations are found in pathways involved in cell cycle regulation, telomere maintenance and WNT signaling. However, no mutations in any of the genes mutated in aldosterone-producing adenomas had been described in ACC.

In this study, our goal was to identify mutations in a set of genes known to confer aldosterone production in APA in ACCs associated with hyperaldosteronism.

\section{Methods}

\section{Tissue microarray (TMA) building}

Formalin-fixed, paraffin-embedded tissue blocks (FFPE) of 141 cases of adrenal cortical cancer, representing 128 patients, were obtained from the files of the Department of Pathology, University of Michigan Medical Center, Ann Arbor, MI, USA and contributing institutions. After pathological review, four TMAs were constructed from the most representative non-necrotic area using the methodology of Nocito et al. (2001). Each case was represented in the array by three $1 \mathrm{~mm}$ diameter cores. Control tissue (ACA, tonsil, testes, kidney, liver and normal adrenal) and colored orientation cores were also arrayed. Cases were randomized regarding placement in the TMAs.

\section{Immunohistochemistry}

Formalin-fixed, paraffin sections from the four TMAs were cut at 5 microns and rehydrated to water. Heat-induced epitope retrieval was performed with FLEX TRS High $\mathrm{pH}$ Retrieval buffer (9.01) for $20 \mathrm{~min}$. After peroxidase blocking, the antibody CYP11B2 mouse monoclonal (41-17B, kindly provided by Dr. Celso Gomez, clone RRID: AB_2650562) (Gomez-Sanchez et al. 2014) was applied at a dilution of 1:1500 at room temperature for $60 \mathrm{~min}$. The FLEX HRP EnVision System was used for detection. $\mathrm{DAB}$ chromagen was then applied for $10 \mathrm{~min}$. Slides were counterstained with Harris Hematoxylin for $5 \mathrm{~s}$ and then dehydrated and coverslipped.

TMA slides stained with CYP11B2 were scored based on staining distribution on a $1-3$ grading system $(<10 \%$ : $1+, 10-50 \%: 2+,>50 \%: 3+)$. Cases which showed possible staining were identified and corresponding full slides were cut and stained for CYP11B2 by the same method as described above. This cohort of full slides was then scored using the same methods as above. The cases identified to show true staining $(2+$ and $3+)$ were characterized by strong staining and contained a mixture of focal and diffuse positivity. Clinical data were then captured for the cases identified.

\section{Retrospective chart review}

Charts were reviewed for laboratory characteristics (pretreatment levels of renin, aldosterone (urine and serum) and potassium), mentioning of diagnosis of PA in physician notes, potassium replacement therapy. Any patient with a physician note stating aldosterone production was included in the initial study as well as patients with laboratory constellation suggestive of PA. The Endocrine Society Guideline suggestions for screening for PA were considered.

\section{DNA extraction}

Genomic DNA (gDNA) was extracted from unstained FFPE slides for AC100-112 and YY for AC113-119, using 
the AllPrep DNA/RNA FFPE kit (QIAGEN) as described previously (Warrick et al. 2015).

\section{Next-generation sequencing}

For each sample, 20 ng of isolated gDNA was used for barcoded library generation by multiplexed PCR using two custom Ion AmpliSeq Panels covering aldosteroneassociated genes (APAv1 for AC100-112 and APAv2 for AC113-119) and cancer-associated genes (OCPv2 for AC100-119) and the Ion AmpliSeq Library kit 2.0 (Life Technologies) according to the manufacturer's instructions. APAv1 was designed to target genes previously shown to be mutated in APA or other adrenal hyperplasias/neoplasms, contains 310 independent primer pairs targeting the entire coding regions of genes with reported somatic mutations in APA (KCNJ5, ATP1A1, $A T P 2 B 3, C A C N A 1 D)$, genes shown to harbor germline or somatic variants associated with adrenal hyperplasia (phosphodiesterase 11A (PDE11A), phosphodiesterase 8B $(P D E 8 B)$, protein kinase, cAMP-dependent, regulatory, type 1, (PRKAR1A)). APAv2 contains 499 independent primer pairs targeting the entire coding regions of genes in APAv1 and genes shown to harbor germline or somatic variants associated with other adrenal diseases (protein kinase, cAMP-dependent, catalytic, (PRAKACA) and armadillo repeat-containing 5 (ARMC5)), $\alpha-1 \mathrm{H}$ subunit of T-type voltage-dependent $\mathrm{Ca}(2+)$ channels (CACNA1H) and oncogene hot spots in guanine nucleotide-binding protein subunit (GNAS) and $\beta$-catenin (CTNNB1). Template preparation and NGS of multiplexed templates were performed as described (Warrick et al. 2015) using Ion 318 Chip v2 on the Ion Torrent Personal Genome Machine (PGM) sequencer (Life Technologies) for samples with APAv1 and Ion PI Chip v3 on the Ion Proton sequencer (Life Technologies) for samples with APAv2. Data analysis was performed essentially as described previously (Warrick et al. 2015).

Briefly, for the samples with APAv1, APAv2 and OCPv2 variants called by default PGM or Proton low stringency variant filtering were further filtered to identify potential driving somatic and germline mutations by removing synonymous or noncoding variants, those with flow corrected read depth $(\mathrm{FDP})<\mathrm{AAA}$, flow corrected variant allele containing reads $(\mathrm{FAO})<\mathrm{BBB}$, variant allele frequencies $(\mathrm{FAO} / \mathrm{FDP})<\mathrm{CCC}$, flow variant allele calling forward to reverse read ratio $<0.2$ or $>5$ or indels within homopolymer runs $\geq 4$. Variants occurring exclusively in reads containing other variants (single nucleotide variants or indels) or those occurring in the last mapped base of a read were excluded. Variants with (1) allele frequencies $>0.5 \%$ in ESP6500 or 1000 genomes or (2) those reported in ESP6500 or 1000 genomes with observed variant allele frequencies between 0.40 and 0.60 or $>0.9$ were considered germline variants unless occurring variants were at known hotspot locations. All variants were visually confirmed in Integrative Genomics Viewer (IGV, Broad Institute, https://www.broadinstitute.org/igv/) (Hovelson et al. 2015).

The study was approved by the Institutional Review Board at the University of Michigan and patients were either consented before the use of their biosamples for the analysis conducted in this study (HUM00024461) or secondary analysis of archived samples was granted with a waiver of consent (HUM00083056).

\section{Results}

We employed two different strategies to identify as many patients as possible with a diagnosis of ACC and concurrent aldosterone production. First, we reviewed charts of 422 patients with a pathologically confirmed diagnosis of ACC for features of hyperaldosteronism and second, we stained an ACC TMA for CYP11B2.

\section{Identification of patients with ACC and aldosterone production}

Patient records were reviewed for a mentioning of aldosterone production documentation of increased aldosterone levels (>15 ng/dL), a plasma aldosterone (ng/dL)-to-renin $(\mathrm{ng} / \mathrm{mL} / \mathrm{h})$ ratio (ARR) of $>20$ or increased 24-h urine aldosterone. A total of 25 patients were identified and tissues of 13 patients were available for further evaluation by immunohistochemistry and sequencing (ACC 1-12, 15) (Table 1). Interestingly, despite the documentation of hyperaldosteronism in the setting of ACC, not all 13 patients were likely to have a diagnosis of PA. PA was the definitive diagnosis in at least three patients (ACC $1,3,6$ ) as they had suppressed renin and aldosterone $>20 \mathrm{ng} / \mathrm{dL}$ in the setting of hypertension and spontaneous hypokalemia, which are the criteria for the diagnosis of primary aldosteronism by the recent Endocrine Society guidelines, in which confirmatory testing can be omitted. Based on clinical features, aldosterone level and ARR, another five patients (ACC 2, 5, 7, 10, 12) had a likely diagnosis of primary aldosteronism. However, none of these patients underwent confirmatory testing at the time of initial diagnosis, likely due to the assumption of a malignant (c) 2019 Society for Endocrinology Published by Bioscientifica Ltd. Printed in Great Britain 
Table 1 Patient and tumor characteristics.

\begin{tabular}{|c|c|c|}
\hline ACC \# & Sex & Age (years) \\
\hline 1 & $\mathrm{M}$ & 66 \\
\hline 2 & $\mathrm{~F}$ & 39 \\
\hline 3 & $\mathrm{~F}$ & 69 \\
\hline 4 & $\mathrm{~F}$ & 48 \\
\hline 5 & $\mathrm{~F}$ & 52 \\
\hline 6 & $\mathrm{~F}$ & 22 \\
\hline 7 & $\mathrm{~F}$ & 43 \\
\hline 8 & $M$ & 49 \\
\hline 9 & $\mathrm{~F}$ & 29 \\
\hline 10 & $\mathrm{~F}$ & 39 \\
\hline 11 & $\mathrm{~F}$ & 51 \\
\hline 12 & $M$ & 24 \\
\hline 13 & $\mathrm{~F}$ & 61 \\
\hline 14 & $\mathrm{~F}$ & 60 \\
\hline 15 & $\mathrm{~F}$ & 49 \\
\hline 16 & $\mathrm{~F}$ & 36 \\
\hline 17 & $\mathrm{~F}$ & 55 \\
\hline 18 & $\mathrm{~F}$ & 25 \\
\hline Total & $3 \mathrm{M} / 15 \mathrm{~F}$ & $45( \pm 14)$ \\
\hline
\end{tabular}

\begin{tabular}{ll}
\cline { 1 - 1 } Side & Alive \\
\cline { 1 - 1 }$R$ & No \\
$R$ & No \\
$L$ & Yes \\
$L$ & Yes \\
$L$ & Yes \\
$R$ & Yes \\
$L$ & No \\
$R$ & No \\
$L$ & Yes \\
$R$ & Yes \\
$R$ & No \\
$R$ & No \\
$R$ & No \\
$R$ & No \\
$L$ & No \\
$L$ & Yes \\
$X$ & No \\
$L$ & No \\
$8 L / 9 R$ & 7 Yes/11 No
\end{tabular}

\begin{tabular}{|c|c|}
\hline OS (months) & Recurrence \\
\hline 91 & Yes \\
\hline 85 & Yes \\
\hline 48 & Yes \\
\hline
\end{tabular}

\begin{tabular}{c}
\hline RFS (months) \\
\hline 62 \\
27
\end{tabular}

25 No

59 No

17 No

34 Yes

119 Yes

37 No

3 No

33 Yes

49 Yes

$6 \mathrm{n} / \mathrm{a}$

$8 \mathrm{n} / \mathrm{a}$

21 Yes

$10 \mathrm{n} / \mathrm{a}$

$\mathrm{n} / \mathrm{a} \quad \mathrm{n} / \mathrm{a}$

$n / a \quad n / a$

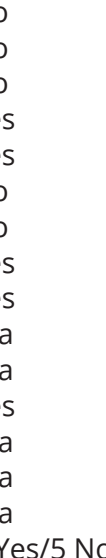

19

25

25
59

59
17

17
23

23
43

43
37

37
3

3
31

31
11

$\mathrm{n} / \mathrm{a}$

n/a

$\mathrm{n} / \mathrm{a}$
7

$\mathrm{n} / \mathrm{a}$

$n / a$

$\mathrm{n} / \mathrm{a}$

$40( \pm 32)$

\begin{tabular}{l} 
Identification \\
\hline CR \\
CR \\
TMA, CR \\
CR \\
CR \\
CR \\
CR \\
CR \\
CR \\
CR \\
CR \\
CR \\
TMA \\
TMA \\
TMA, CR \\
TMA \\
TMA \\
TMA \\
13 CR/7 TMA
\end{tabular}

\begin{tabular}{l}
\hline Stage \\
\hline 2 \\
2 \\
2 \\
3 \\
3 \\
3 \\
1 \\
2 \\
2 \\
2 \\
3 \\
3 \\
4 \\
4 \\
2 \\
4 \\
$n / a$ \\
$n / a$ \\
$1(1)$ \\
$2(7)$ \\
$3(5)$ \\
$4(3)$ \\
\hline
\end{tabular}

\begin{tabular}{|c|c|}
\hline Grade & Size $(\mathrm{cm})$ \\
\hline 1 & 8 \\
\hline 1 & 6.5 \\
\hline 1 & 9 \\
\hline 1 & 16 \\
\hline 1 & 10 \\
\hline 1 & 13.5 \\
\hline 2 & 4.5 \\
\hline 2 & 8 \\
\hline 2 & 10.5 \\
\hline 2 & 12 \\
\hline 2 & 11 \\
\hline 2 & 9 \\
\hline 2 & 25 \\
\hline 2 & 25 \\
\hline 2 & 8.7 \\
\hline 1 & 16 \\
\hline 1 & $\mathrm{n} / \mathrm{a}$ \\
\hline 2 & na \\
\hline
\end{tabular}

$1(8)$

$12( \pm 6)$

\section{$---$}

ACC, adrenocortical carcinoma; CR, retrospective chart review; F, female; L, left; M, male; OS, overall survival; R, right; RFS, recurrence free survival; TMA, tissue microarray.

mass and little impact on care. Only one patient with a low suspicion for PA underwent 24-h urine collection with a final value of $330 \mu \mathrm{g} / \mathrm{L} / 24 \mathrm{~h}$ (ACC 12). Two patients had hyperreninemic hyperaldosteronism (HH) (ACC 11, 15) and for another three patients, clinical data were insufficient for subclassification of hyperaldosteronism into PA or hyperreninemic hyperaldosteronism (ACC 4,8 , 9). However, all three patients had spontaneous hypokalemia and required potassium supplementation in the absence of significant hypercortisolism.

In order to evaluate the 13 clinically identified subjects for molecular correlates of aldosterone production, tissue sections were stained for CYP11B2 protein. Nine of the 13 patients showed positive staining for CYP11B2. However, intensity and distribution varied greatly from only small islands or single cells with positive staining to nearly entire staining of the whole specimen (Fig. 1). Of the four patients whose specimen stained negative, two clearly had a clinical diagnosis of PA (ACC 1, 12), one only had a mentioning of PA in the clinical notes without any further data available (ACC 4), and another patient likely carried the diagnosis of hyperreninemic hyperaldosteronism as judged by available biochemical data (ACC 11). Therefore, it is likely that the source of aldosterone in patients with samples with negative staining was either the contralateral adrenal gland or a different subclone of the often large adrenal tumors, which were not available for analysis.

\section{Identification of patients with ACC and aldosterone production by tissue microarrays (TMA) staining for CYP11B2}

In the second separate approach, ACC TMAs, containing 141 different specimens, including specimens of 118 patients that were also part of the initial 422 patients available for chart review, were stained for CYP11B2 and full slides were used to confirm staining. From the CYP11B2-stained TMA slides, we identified 57 cases of possible positive CYP11B2 staining. Full slide CYP11B2 staining, confirmed a total of seven ACC samples with true positive staining (Fig. 1 and Table 1). Five of these samples were not included in the initial retrospective chart review.

Of the initial 13 patients identified by retrospective chart review, a total of 7 patients were included in the TMA. Two of these seven samples had high and moderate CYP11B2 staining and were correctly identified in this second approach. The remaining five patients showed only minimal focal staining or were entirely negative on CYP11B2 staining and therefore escaped identification by TMA staining.

Clinical data were subsequently collected from all patients identified by CYP11B2 staining. However, there was only a renin value for a single patient available, which was clearly elevated and suggestive of hyperreninemic hyperaldosteronism (ACC 14). 


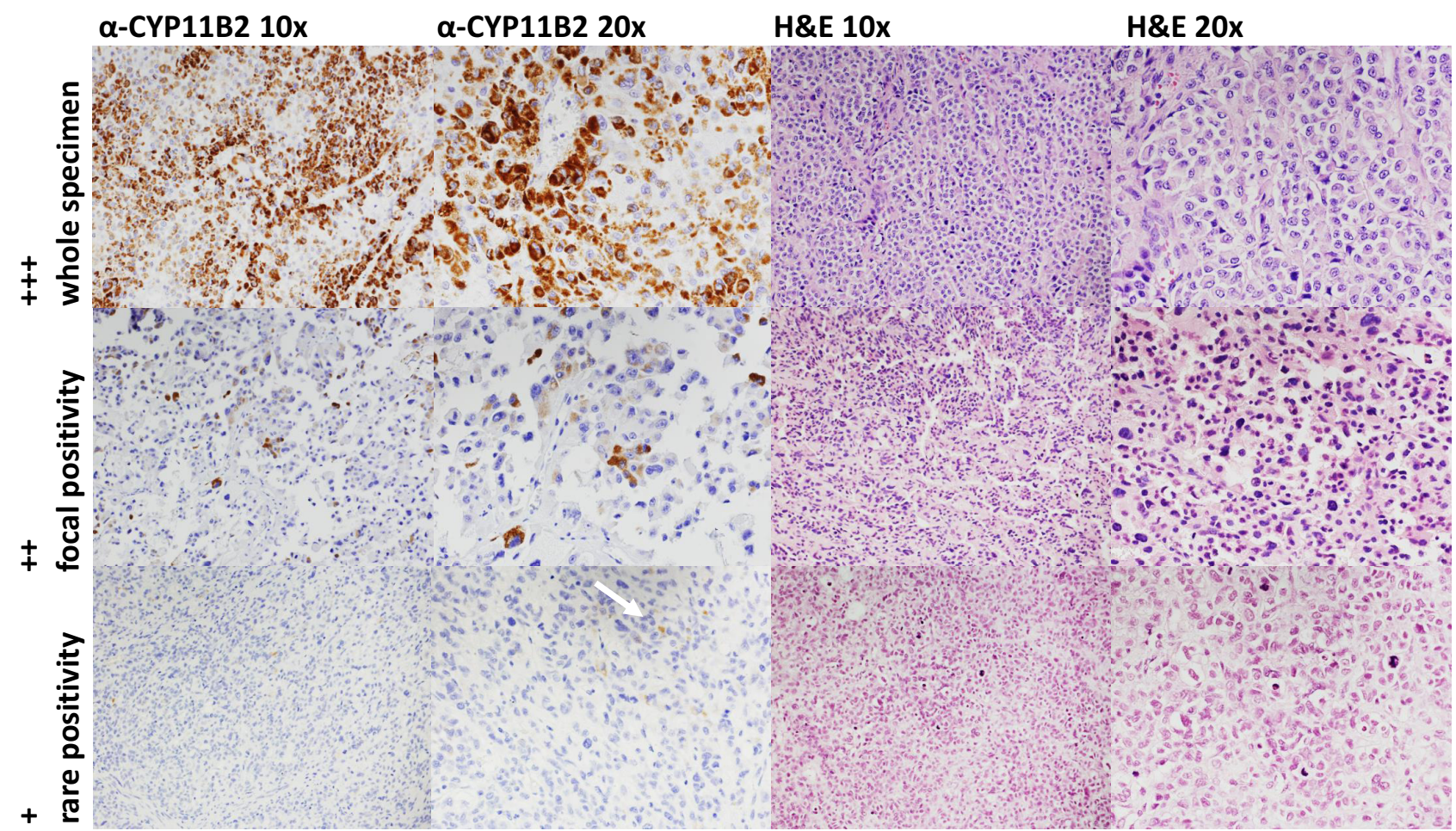

Figure 1

Representative IHC for CYP11B2. Left two panels - CYP11B2 (10x and 20x), right two panels H\&E (10x and 20x).

The total number of patients identified as potential PA by the two methods was 18 .

\section{Demographics of identified patients}

As described above, a total of 18 patients were identified as possible cases of PA. Of these patients, the sex distribution was $83 \%$ female (15/18) and $17 \%$ male (3/18) (Table 2$)$. The age range was 22-69 with an average age of 45 years. One patient was diagnosed at stage 1 , seven patients at stage 2 and five patients at stage 3 . Three patients had metastasized ACC at the time of diagnosis. The stage at diagnosis was unavailable for two patients. Tumor grading was available for all tumors with eight tumors being low grade ( $\leq 20$ mitosis per $50 \mathrm{hpf}$ ) and ten tumors being high grade ( $>20$ mitosis per $\mathrm{hpf}$ ). Eight tumors were on the left side, nine on the right and one tumor specimen was obtained from a metastasis.

\section{Somatic genetic alterations}

DNA was isolated from FFPE samples and subjected to two different NGS custom panels, a panel sequencing mutations in genes known to be associated with PA in adrenal adenomas (Supplementary Table 1, see section on supplementary data given at the end of this article) and the DNA component of the Oncomine Comprehensive Assay (OCP), a pan-cancer panel targeting 135 genes recurrently altered through somatic mutation or high level copy number amplification/loss that is being used in the NCI MATCH trial (Supplementary Table 2). The average coverage for the samples on APAv1 was 401.5X and on APAv2 was 2046X. None of the ACCs, including the ACCs, which showed autonomous aldosterone production (true primary aldosteronism) (Table 2), harbored well-supported mutations in the aldosterone production-associated genes. One patient (ACC 14) had a likely germline variant of uncertain significance in ATP2B3 (c.3518T, p.A1173V, NM_001001344).

Using the OCP, six ACCs had activating CTNNB1 mutations and four ACCs displayed TP53 mutations (Fig. 2A). In accordance with recently published molecular landscape analysis, deleterious mutations in several other known tumor suppressors were found (e.g. CDKN2A, PRKAR1A, ATM, RB1) (Assie et al. 2014, Juhlin et al. 2015, Zheng et al. 2016). Somatic genomic losses and gains also mirrored recent publications with amplifications of TERT and PIK3R1 and losses of CDKN2A (Fig. 2B).

Interestingly, one tumor harbored a mutation in APEX1, which had been implied in regulation of the
(C) 2019 Society for Endocrinology Published by Bioscientifica Ltd. Printed in Great Britain 
Table 2 Endocrine characteristics of patients and tumor samples.

\begin{tabular}{|c|c|c|c|c|c|c|c|}
\hline ACC \# & HC & HA & Aldo (ng/dL) & $\operatorname{Renin}(\mathrm{ng} / \mathrm{mL} / \mathrm{h})$ & ARR & K & K suppl \\
\hline 1 & No & No & 30.9 & 0.2 & 154.5 & 3.4 & Yes \\
\hline 2 & No & No & 51.3 & 1.4 & 36.6 & 2.5 & Yes \\
\hline 3 & Yes & No & 22.4 & 0.1 & 224 & 2.3 & Yes \\
\hline 4 & No & No & $\mathrm{n} / \mathrm{a}$ & $\mathrm{n} / \mathrm{a}$ & n/a & 2.3 & Yes \\
\hline 5 & Yes & Yes & 16.2 & 0.6 & 27.9 & 3.2 & No \\
\hline 6 & No & No & 22 & 0.5 & 44 & 3 & $\mathrm{n} / \mathrm{a}$ \\
\hline 7 & No & No & 51 & 2.1 & 24.3 & 2.8 & Yes \\
\hline 8 & No & No & $\mathrm{n} / \mathrm{a}$ & $\mathrm{n} / \mathrm{a}$ & $\mathrm{n} / \mathrm{a}$ & bnr & Yes \\
\hline 9 & No & No & 28 & $\mathrm{n} / \mathrm{a}$ & $\mathrm{n} / \mathrm{a}$ & 2.8 & Yes \\
\hline 10 & No & No & 11.4 & 0.4 & 28.5 & $\mathrm{nl}$ & No \\
\hline 11 & Yes & No & 20.4 & 6.9 & 3 & 2.8 & Yes \\
\hline 12 & Yes & No & $5.8^{*}$ & 0.5 & 11.6 & 2.3 & Yes \\
\hline 13 & Yes & Yes & $\mathrm{n} / \mathrm{a}$ & $\mathrm{n} / \mathrm{a}$ & $\mathrm{n} / \mathrm{a}$ & $\mathrm{nl}$ & Yes \\
\hline 14 & Yes & No & $\mathrm{n} / \mathrm{a}$ & 47.4 & $\mathrm{n} / \mathrm{a}$ & $\mathrm{nl}$ & Yes \\
\hline 15 & No & Yes & 221.5 & 6.3 & 35.2 & 2.8 & Yes \\
\hline 16 & Yes & No & $\mathrm{n} / \mathrm{a}$ & $\mathrm{n} / \mathrm{a}$ & $\mathrm{n} / \mathrm{a}$ & $\mathrm{nl}$ & $\mathrm{n} / \mathrm{a}$ \\
\hline 17 & $\mathrm{n} / \mathrm{a}$ & $\mathrm{n} / \mathrm{a}$ & $\mathrm{n} / \mathrm{a}$ & $\mathrm{n} / \mathrm{a}$ & $\mathrm{n} / \mathrm{a}$ & $\mathrm{n} / \mathrm{a}$ & $\mathrm{n} / \mathrm{a}$ \\
\hline 18 & $\mathrm{n} / \mathrm{a}$ & $\mathrm{n} / \mathrm{a}$ & $\mathrm{n} / \mathrm{a}$ & $\mathrm{n} / \mathrm{a}$ & $\mathrm{n} / \mathrm{a}$ & $\mathrm{n} / \mathrm{a}$ & $\mathrm{n} / \mathrm{a}$ \\
\hline
\end{tabular}

\begin{tabular}{|c|c|}
\hline HTN & Documentation \\
\hline Yes & PA \\
\hline Yes & PA \\
\hline Yes & PA \\
\hline Yes & $\mathrm{PA}$ \\
\hline Yes & $x$ \\
\hline Yes & PA \\
\hline Yes & PA \\
\hline Yes & PA \\
\hline Yes & $x$ \\
\hline Yes & PA \\
\hline Yes & PA \\
\hline Yes & PA \\
\hline Yes & $x$ \\
\hline Yes & $x$ \\
\hline Yes & PA vs $\mathrm{HH}$ \\
\hline Yes & $x$ \\
\hline $\mathrm{n} / \mathrm{a}$ & $x$ \\
\hline $\mathrm{n} / \mathrm{a}$ & $x$ \\
\hline
\end{tabular}

\begin{tabular}{cll}
\cline { 1 - 1 } \cline { 2 - 2 } CYP11B2 score & & Clinical diagnosis \\
\cline { 1 - 2 }+ & PA \\
+ & PA \\
++ & PA \\
- & PA $/ \mathrm{HH}$
\end{tabular}

*Urine aldosterone $303 \mu \mathrm{g} / 24 \mathrm{~h}$.

Aldo, aldosterone; ARR, aldosterone-renin ratio; HA, hyperandrogenemia; HC, hypercortisolism; HH, hyperreninemic hyperaldosteronism; IND, indeterminate; $\mathrm{K}$, potassium; $\mathrm{K}$ suppl, potassium supplementation; PA, primary aldosteronism.

CYP11B2 locus (McManus et al. 2012). Two patients were found to have likely germline predisposing mutations causing Lynch syndrome (MSH2), which is in accordance with prior studies (Raymond et al. 2013). One of these patients in addition had the commonly observed CHEK2 founder mutation (c.1100delC). Other variants in genes associated with hereditary diseases were likely somatic mutations (e.g. APC, CDKN2A, BRCA2).

\section{Discussion}

In summary, a total of 18 patients with a diagnosis of ACC and features of hyperaldosteronism were identified using the combined approach of retrospective chart review (13 patients) and TMA CYP11B2 staining (seven patients, two identified in both). It is important to note that not all ACC patients in this series had autonomous aldosterone production and true primary aldosteronism. We aimed to capture a maximum number of patients with ACC and concurrent hyperaldosteronism. In further interpretation of clinical data, the patients were subtyped into primary aldosteronism (PA), hyperreninemic hyperaldosteronism $(\mathrm{HH})$, equivocal or indeterminate groups (Table 2 ). The diagnosis of primary aldosteronism rarely impacts therapy for ACC, which is most commonly treated surgically. Therefore, confirmatory testing, which is standard for primary aldosteronism due to benign causes, is seldom pursued. In our case series three patients fulfilled these strict criteria and can be categorized as true PA. For another five patients the diagnosis of PA was likely based on clinical data and three patients had a possible diagnosis of PA. Interestingly, three patients could be characterized as hyperreninemic hyperaldosteronism.

In summary, the available clinical data suggest that aldosterone production is autonomous and independent from the renin-angiotensin system in the majority of ACCs associated with hyperaldosteronism, like in aldosterone-producing adenomas. There are several explanations that can be considered for the pathophysiology of hyperreninemic hyperaldosteronism, observed in a subset of patients: (1) ACCs could preserve responsiveness to angiotensin II (AngII), (2) in some cases elevated renin production might originate from the ACC as a paraneoplastic phenomenon or (3) more likely, be of renoparenchymal origin due to compression of the kidney or renal vasculature by the often large tumors (Iimura et al. 1986, Maas et al. 2007). Although in vivo evidence is lacking to support the first possibility, there is ample evidence from published studies using NCI-H295 derived subclones (e.g. HAC15) as a model for AngII responsiveness (Parmar et al. 2008). HAC15 cells express CYP11B2 upon AngII stimulation and produce aldosterone. In the latter two instances aldosterone production might have originated from the remaining ipsilateral adrenal tissue or the contralateral adrenal gland. These data are well in accordance with another large series that analyzed ACC https://erc bioscientifica com

https://doi.org/10.1530/ERC-18-0385
2019 Society for Endocrinology Published by Bioscientifica Ltd. Printed in Great Britain 
A
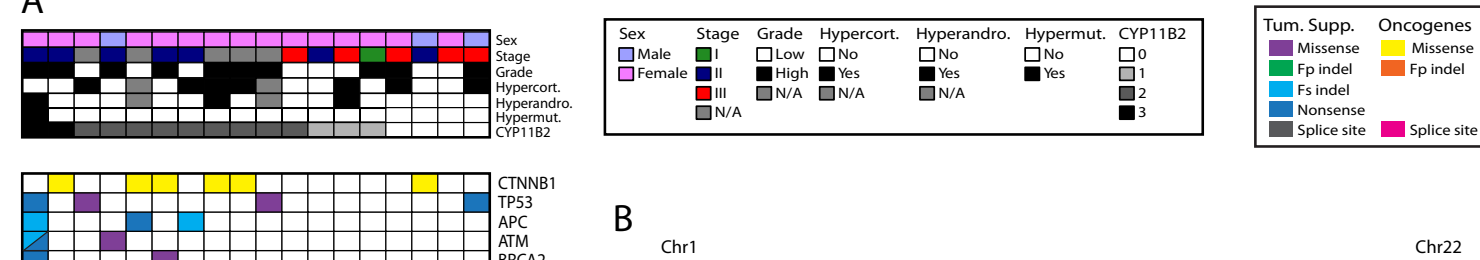

B
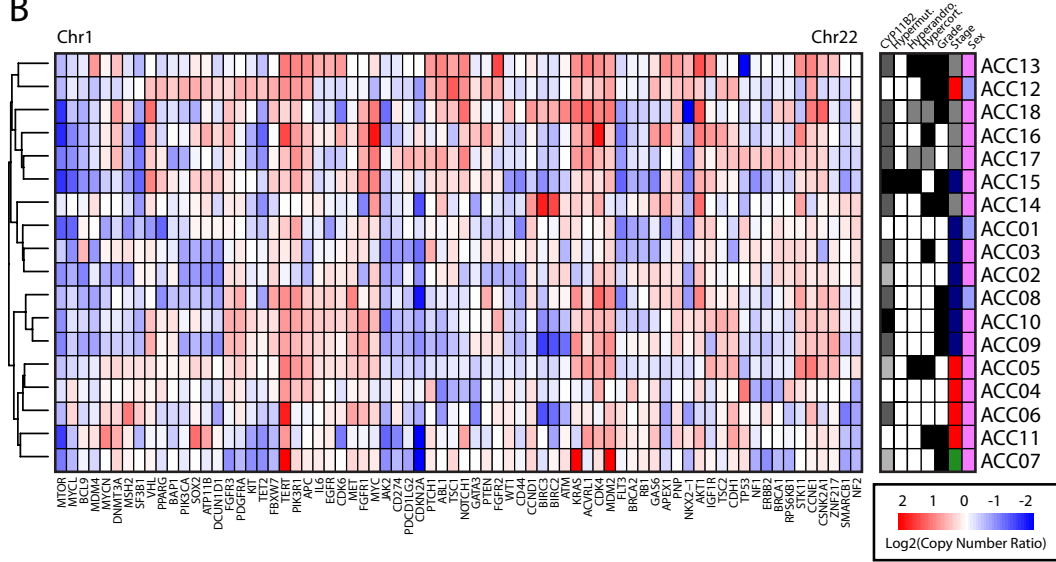

Figure 2

Mutational landscape of aldosterone producing ACC. (A) Upper panel: clinical and tumor characteristics. Lower panel: genes carrying variants, mutations and indels (B) left panel: amplifications and deletions derived from next-generation sequencing sets on respective chromosomes, right panel: clinical and tumor characteristics.

with hyperaldosteronism, in which at least $17 \%$ of all patients did not have suppressed renin levels (Seccia et al. 2005).

When relying on retrospective clinical data, it is a limitation that aldosterone levels are most commonly measured by immunoassay and therefore cross-reactivity with for example, 11-deoxycorticosterone cannot be excluded. The use of a TMA bears the risk of identifying ACCs with CYP11B2 staining, which do not have other prerequisites for aldosterone production (e.g. missing expression of other steroidogenic enzymes). However, the identification of the two patients with generalized staining with both methods out of a large cohort of patients is reassuring. Therefore, the inclusion of all of these cases in the molecular analysis is justified as they potentially represent ACCs with autonomous aldosterone production.

With regards to the somatic mutational profile we analyzed known oncogenes and tumor suppressor genes. The observed mutations are well in accordance with prior publications, suggesting involvement of WNT signaling and cell cycle regulation in the pathogenesis of ACC. In summary, no unique mechanisms of molecular tumorigenesis were observed in ACCs associated with hyperaldosteronism compared to other ACC.

The majority of APAs (70-90\%) carry specific mutations in genes altering cell membrane polarization and intracellular calcium levels. In ACC, however, we did not find any mutation in these genes. We only found a monoallelic variant of undetermined significance in ATP2B3 (likely germline) and APEX1, which have been implicated in APA pathogenesis and CYP11B2 gene regulation, respectively. Although our twopronged approach of identification also included ACCs with hyperaldosteronism driven by hyperreninemic hyperaldosteronism, the molecular analysis and conclusion is still valid as the group included several ACCs with a greater likelihood for true autonomous aldosterone production. Although we cannot exclude that some subclones of aldosterone-producing ACC potentially carry mutations in the same genes as described in APA, our data are suggestive for a different mechanism of aldosterone production in aldosterone-producing ACCs. This is well in accordance with the general clinical observation that APAs rarely progress to ACC. Although case reports have shown the occurrence of ACC in patients with prior adrenal nodules or adenomas, it is still a matter of debate, whether ACCs arise from adenomas as shown for other organs (Nogueira et al. 2015, Belmihoub et al. 2017). In addition, APAs might be diagnosed early and subjected to surgery and therefore progression is rarely observed.

In summary, aldosterone production in patients with ACC and hyperaldosteronism can be caused by different mechanisms and a full biochemical evaluation is needed
2019 Society for Endocrinology Published by Bioscientifica Ltd. Printed in Great Britain 
to define the underlying pathophysiology, primary aldosteronism or hyperreninemic hyperaldosteronism. ACCs associated with hyperaldosteronism harbor similar mutations and a similar profile of genomic gains and losses as ACCs without aldosterone production. As no classical APA-associated mutations were found, we conclude that molecular events conferring aldosterone production in ACC are likely different from those in aldosteroneproducing adenomas.

\section{Supplementary data}

This is linked to the online version of the paper at https://doi.org/10.1530/ ERC-18-0385.

\section{Declaration of interest}

S A T is supported by the A. Alfred Taubman Medical Research Institute. $S$ A T has received travel support from and had a sponsored research agreement with Compendia Bioscience/Life Technologies/ThermoFisher Scientific that provided access to one of targeted sequencing panel used herein. No other aspect of this study was supported by Compendia Bioscience/Life Technologies/ThermoFisher. D H has received travel support from ThermoFisher Scientific. S A T is a co-founder of, consultant for and Laboratory Director of Strata Oncology. Tobias Else is a member of the Editorial Board of Endocrine-Related Cancer. The other authors have no competing interests to declare.

\section{Funding}

AHA (14SDG17990000) to T E, NHLBI (1R01HL130106) to T E and W E R, NIDDK to (Grant R01 DK106618) to W E R and S A T.

\section{References}

Assie G, Letouzé E, Fassnacht M, Jouinot A, Luscap W, Barreau O, Omeiri H, Rodriguez S, Perlemoine K, René-Corail F, et al. 2014 Integrated genomic characterization of adrenocortical carcinoma. Nature Genetics 46 607-612. (https://doi.org/10.1038/ng.2953)

Belmihoub I, Silvera S, Sibony M, Dousset B, Legmann P, Bertagna X, Bertherat J \& Assie G 2017 From benign adrenal incidentaloma to adrenocortical carcinoma: an exceptional random event. European Journal of Endocrinology 176 K15-K19. (https://doi.org/10.1530/EJE17-0037)

Beuschlein F, Boulkroun S, Osswald A, Wieland T, Nielsen HN, Lichtenauer UD, Penton D, Schack VR, Amar L, Fischer E, et al. 2013 Somatic mutations in ATP1A1 and ATP2B3 lead to aldosteroneproducing adenomas and secondary hypertension. Nature Genetics 45 440-4, 444e1. (https://doi.org/10.1038/ng.2550)

Choi M, Scholl UI, Yue P, Björklund P, Zhao B, Nelson-Williams C, Ji W, Cho Y, Patel A, Men CJ, et al. $2011 \mathrm{~K}+$ channel mutations in adrenal aldosterone-producing adenomas and hereditary hypertension. Science 331 768-772. (https://doi.org/10.1126/science.1198785)

Else T, Kim AC, Sabolch A, Raymond VM, Kandathil A, Caoili EM, Jolly S, Miller BS, Giordano TJ \& Hammer GD 2014a Adrenocortical carcinoma. Endocrine Reviews 35 282-326. (https://doi.org/10.1210/ er.2013-1029)

Else T, Williams AR, Sabolch A, Jolly S, Miller BS \& Hammer GD $2014 b$ Adjuvant therapies and patient and tumor characteristics associated with survival of adult patients with adrenocortical carcinoma. Journal of Clinical Endocrinology and Metabolism 99 455-461. (https:// doi.org/10.1210/jc.2013-2856)

Gomez-Sanchez CE, Qi X, Velarde-Miranda C, Plonczynski MW, Parker CR, Rainey W, Satoh F, Maekawa T, Nakamura Y, Sasano H, et al. 2014 Development of monoclonal antibodies against human CYP11B1 and CYP11B2. Molecular and Cellular Endocrinology 383 111-117. (https://doi.org/10.1016/j.mce.2013.11.022)

Hovelson DH, McDaniel AS, Cani AK, Johnson B, Rhodes K, Williams PD, Bandla S, Bien G, Choppa P, Hyland F, et al. 2015 Development and validation of a scalable next-generation sequencing system for assessing relevant somatic variants in solid tumors. Neoplasia 17 385-399. (https://doi.org/10.1016/j. neo.2015.03.004)

Iimura O, Shimamoto K, Hotta D, Nakata T, Mito T, Kumamoto Y, Dempo K, Ogihara T \& Naruse K 1986 A case of adrenal tumor producing renin, aldosterone, and sex steroid hormones. Hypertension 8 951-956. (https://doi.org/10.1161/01.HYP.8.10.951)

Juhlin CC, Goh G, Healy JM, Fonseca AL, Scholl UI, Stenman A, Kunstman JW, Brown TC, Overton JD, Mane SM, et al. 2015 Wholeexome sequencing characterizes the landscape of somatic mutations and copy number alterations in adrenocortical carcinoma. Journal of Clinical Endocrinology and Metabolism 100 E493-E502. (https://doi. org/10.1210/jc.2014-3282)

Maas MH, Cransberg K, van Grotel M, Pieters R \& van den HeuvelEibrink MM 2007 Renin-induced hypertension in Wilms tumor patients. Pediatric Blood and Cancer 48 500-503. (https://doi. org/10.1002/pbc.20938)

McManus F, Sands W, Diver L, MacKenzie SM, Fraser R, Davies E \& Connell JM 2012 APEX1 regulation of aldosterone synthase gene transcription is disrupted by a common polymorphism in humans. Circulation Research 111 212-219. (https://doi.org/10.1161/ CIRCRESAHA.111.262931)

Monticone S, Else T, Mulatero P, Williams TA \& Rainey WE 2015 Understanding primary aldosteronism: impact of next generation sequencing and expression profiling. Molecular and Cellular Endocrinology 399 311-320. (https://doi.org/10.1016/j. mce.2014.09.015)

Nocito A, Kononen J, Kallioniemi OP \& Sauter G 2001 Tissue microarrays (TMAs) for high-throughput molecular pathology research. International Journal of Cancer 94 1-5. (https://doi. org/10.1002/ijc.1385)

Nogueira TM, Lirov R, Caoili EM, Lerario AM, Miller BS, Fragoso MC, Dunnick NR, Hammer GD \& Else T 2015 Radiographic characteristics of adrenal masses preceding the diagnosis of adrenocortical cancer. Hormones and Cancer 6 176-181. (https://doi.org/10.1007/s12672015-0225-2)

Parmar J, Key RE \& Rainey WE 2008 Development of an adrenocorticotropin-responsive human adrenocortical carcinoma cell line. Journal of Clinical Endocrinology and Metabolism 93 4542-4546. (https://doi.org/10.1210/jc.2008-0903)

Raymond VM, Everett JN, Furtado LV, Gustafson SL, Jungbluth CR, Gruber SB, Hammer GD, Stoffel EM, Greenson JK, Giordano TJ, et al. 2013 Adrenocortical carcinoma is a lynch syndrome-associated cancer. Journal of Clinical Oncology 31 3012-3018. (https://doi. org/10.1200/JCO.2012.48.0988)

Scholl UI, Goh G, Stölting G, de Oliveira RC, Choi M, Overton JD, Fonseca AL, Korah R, Starker LF, Kunstman JW, et al. 2013 Somatic and germline CACNA1D calcium channel mutations in aldosteroneproducing adenomas and primary aldosteronism. Nature Genetics $\mathbf{4 5}$ 1050-1054. (https://doi.org/10.1038/ng.2695)

Scholl UI, Stölting G, Nelson-Williams C, Vichot AA, Choi M, Loring E, Prasad ML, Goh G, Carling T, Juhlin CC, et al. 2015 Recurrent gain of function mutation in calcium channel CACNA1H causes earlyonset hypertension with primary aldosteronism. ELife 4 e06315. (https://doi.org/10.7554/eLife.06315) https://erc.bioscientifica.com

https://doi.org/10.1530/ERC-18-0385 (c) 2019 Society for Endocrinology Published by Bioscientifica Ltd. Printed in Great Britain 
Seccia TM, Fassina A, Nussdorfer GG, Pessina AC \& Rossi GP 2005 Aldosterone-producing adrenocortical carcinoma: an unusual cause of Conn's syndrome with an ominous clinical course. EndocrineRelated Cancer 12 149-159. (https://doi.org/10.1677/erc.1.00867)

Warrick JI, Hovelson DH, Amin A, Liu CJ, Cani AK, McDaniel AS, Yadati V, Quist MJ, Weizer AZ, Brenner JC, et al. 2015 Tumor evolution and progression in multifocal and paired non-invasive/ invasive urothelial carcinoma. Virchows Archiv 466 297-311. (https:// doi.org/10.1007/s00428-014-1699-y)

Zheng S, Cherniack AD, Dewal N, Moffitt RA, Danilova L, Murray BA, Lerario AM, Else T, Knijnenburg TA, Ciriello G, et al. 2016 Comprehensive pan-genomic characterization of adrenocortical carcinoma. Cancer Cell 30 363. (https://doi.org/10.1016/j. ccell.2016.07.013)

Received in final form 5 November 2018

Accepted 19 November 2018

Accepted Preprint published online 19 November 2018
(C) 2019 Society for Endocrinology Published by Bioscientifica Ltd. Printed in Great Britain 